\title{
Panorama of fetal malformations at the maternity of Treichville teaching hospital (Abidjan - Côte d'Ivoire)
}

\author{
Ignace N'guessan Yao*, Jean-Marc Lamine Dia, Mouhideen Adunfé Oyeladé, Paul-Eric \\ Kouamé Bohoussou, Edouard Konan N'guessan, Gérard Okon, \\ Privat Yéret Guié, Simplice Danho Anongba
}

Department of Obstetrics and Gynecology, Treichville Teaching Hospital, Abidjan-Côte d'Ivoire

Received: 26 May 2017

Accepted: 24 June 2017

\section{*Correspondence: \\ Dr. Ignace N'guessan YAO, \\ E-mail: yaoignacen@yahoo.fr}

Copyright: (C) the author(s), publisher and licensee Medip Academy. This is an open-access article distributed under the terms of the Creative Commons Attribution Non-Commercial License, which permits unrestricted non-commercial use, distribution, and reproduction in any medium, provided the original work is properly cited.

\section{ABSTRACT}

Background: Congenital malformation is responsible for spontaneous abortion, the birth of a child born dead or a child with disabilities that can lead to long-term disability and have a detrimental impact on the individual, his family and society. The etiologies are diverse. The discovery in our maternity is not rare. The absence and high cost of these prenatal diagnostic are a brake on the detection of congenital malformations. It is these various malformations diagnosed in the ante natal and at birth in our service that we describe in this work which aims to make their panorama.

Methods: The purpose of this cross-sectional and descriptive study curried out between 1 January 2003 and 31 December 2013 (10 years) was to describe the various congenital malformations observed at the maternity of the Gynecology and Obstetrics ward of the Treichville University Hospital Center and to identify the socio-demographic characteristics of mothers. This study concerned all women who had given birth at the Treichville University Hospital Center and whose child had a malformation.

Results: During the period, 151 parturients gave birth to at least one child with a congenital malformation and among 30,698 newborns, 161 newborns $(0.52 \%)$ had a malformation. Pregnant women were between 20 and 30 years old $(66 \%)$, were primiparous in $46.4 \%$ of the cases, and $41.7 \%$ were housewives. The malformations were isolated in 101 newborns (62.4\%), multiple in 60 newborns (37.6\%), and dominated by those of the osteoarticular system and the nervous system. Fetal malformations had a poor prognosis in 77 cases (48\%) and the fetus was stillborn in 44 cases $(27 \%)$.

Conclusions: Congenital malformations are a reality at the maternity clinic at Treichville. In our countries, the ultrasound stays a fundamental element for the congenital diagnosis of the malformations. A good training of the doctors in prenatal diagnosis is also necessary to make of good diagnoses who will allow a better care of new-born.

Keywords: Congenital malformation, Prenatal diagnosis, Treichville university hospital center

\section{INTRODUCTION}

Congenital malformation is defined by the WHO as any organic abnormality present at birth even if it is not apparent or immediately detectable. ${ }^{1}$ It is responsible for spontaneous abortion, the birth of a child born dead or a child with disabilities that can lead to long-term disability and have a detrimental impact on the individual, his family and society. ${ }^{1}$ The etiologies are diverse, grouped into four main groups: Genetics, Environmental, Multifactorial and Idiopathic. The discovery in the maternity of a malformed child has become rare in the 
developed countries because of the antenatal diagnosis which allows the detection of the majority of malformations before the birth. ${ }^{2}$ Unfortunately, this is not the case in our developing countries or the failure to monitor pregnancies. The absence and high cost of these prenatal diagnostic are a brake on the detection of congenital malformations. Most of the congenital malformations in our context are discovered in the maternity and are very varied with several types of malformations sometimes in the same newborn. It is these various malformations diagnosed in the ante natal and at birth in our service that we describe in this work which aims to make their panorama.

\section{METHODS}

This is a transversal and descriptive study was conducted over a period of ten (10) years from January $1^{\text {st }} 2003$ to December $31^{\text {st }} 2013$ at the maternity service Gynecology and Obstetrics of the University Hospital of Treichville. We included in our study all patients who gave birth in our department of a child with a malformation revealed on ultrasound and / or discovered in the delivery room after birth. Thus, out of 228 cases we recorded, only 151 cases were recorded, the files of the patients having given birth in another maternity and then evacuated in our department, and the incomplete files were not retained. The various parameters studied were the socioepidemiological characteristics, The gynecological and obstetric history of the pregnant, the characteristics of the newborns and the characteristics of the malformations. Data were collected from patient records and birth records. The processing and analysis of the data was carried out with the Windows Excel and EPI INFO software version 7.1.3.10.

\section{RESULTS}

Table 1: Demographics of patients.

\begin{tabular}{|l|l|l|}
\hline Age & Number of employees & $\%$ \\
\hline$\leq 19$ years & 5 & 3.3 \\
\hline 20-30 years & 100 & 66 \\
\hline$>$ 30 years & 46 & 30.7 \\
\hline Delivery & & \\
\hline 1 & 38 & 25 \\
\hline $2-3$ & 92 & 60 \\
\hline$\geq 4$ & 21 & 14 \\
\hline Parity & & \\
\hline 1 & 70 & 46.4 \\
\hline 2 to 3 & 41 & 27.1 \\
\hline 4 and more & 40 & 26.5 \\
\hline Profession & & \\
\hline Frame & 10 & 6.7 \\
\hline Trader & 38 & 25 \\
\hline Student & 24 & 16 \\
\hline Housewife & 63 & 41.7 \\
\hline Informal sector & 16 & 10.6 \\
\hline
\end{tabular}

\section{Frequency}

We have identified the period from January $1^{\text {st }} 2003$ to December $31^{\text {st }} 2013,151$ women in childbirth of at-least one child with congenital malformation. Of 30, 698 babies born during these 10 years, 161 babies $(0.52 \%)$ had a malformation.

\section{Characteristics of patients}

The characteristics of the patients are summarized in Table 1.

\section{Fetal malformations}

The malformations were isolated in 101 newborns $(62.4 \%)$, and multiple in 60 newborns $(37.6 \%)$. These various malformations are shown in Figure 1.

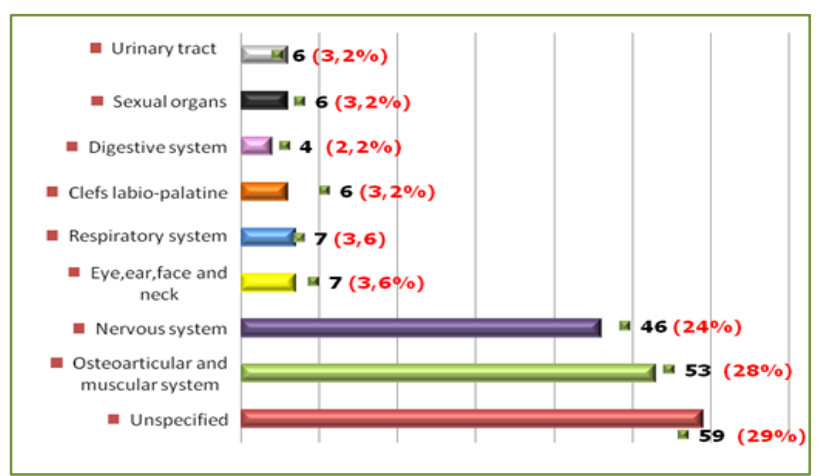

Figure 1: Classification of malformations by organ.

The malformations are predominated by those of the osteoarticular system and the nervous system. The malformations of the nervous system and of the osteoarticular system and of the muscles are summarized in Table 2 and Table 3. Malformations of the nervous system were dominated by macrocephaly. The clubfoot was the predominant malformation.

Table 2: Classification of malformations of the nervous system.

\begin{tabular}{|llc|}
\hline $\begin{array}{l}\text { Congenital malformations of the } \\
\text { nervous system }\end{array}$ & Effective & $\%$ \\
\hline Animals & 04 & 09.3 \\
\hline Spina bifida & 06 & 14.0 \\
\hline Macrocephalia & 21 & 48.7 \\
\hline Hydrocephalus & 06 & 14.0 \\
\hline Myelomeningocele & 03 & 07.0 \\
\hline Microcephalia & 03 & 07.0 \\
\hline Total & 43 & 100 \\
\hline
\end{tabular}

Characteristics of pregnancy, childbirth and condition of newborn

The newborns were ultimately in $75 \%$ of cases, and prematurely in $25 \%$ of cases. Fetal malformations had an echographic diagnosis in $26 \%$, and were found in the 
delivery room in $74 \%$. Ultrasound features are summarized in Table 4.

Table 3: Classification of malformations of musculoskeletal system and muscles.

\begin{tabular}{|lll|}
\hline $\begin{array}{l}\text { Malformations of } \\
\text { musculoskeletal system and } \\
\text { muscles }\end{array}$ & Effective & $\%$ \\
\hline Agenesis members and adactily & 05 & 09.4 \\
\hline Shortening a member & 04 & 07.5 \\
\hline Polydactylia & 03 & 05.6 \\
\hline Palm finger & 01 & 02.0 \\
\hline Clubfoot & 19 & 35.9 \\
\hline Laparoschisis & 03 & 05.6 \\
\hline Kneep deformation & 05 & 09.4 \\
\hline Hand deformation & 02 & 03.8 \\
\hline Omphalocele & 06 & 11.3 \\
\hline Deformation of crane and face & 04 & 07.5 \\
\hline Other toe deformations & 01 & 02.0 \\
\hline Total & 53 & 100 \\
\hline
\end{tabular}

Infant delivery was by birth for 80 newborns (53\%), caesarean section for $71(47 \%)$. These abnormalities had a poor prognosis in 77 cases $(48 \%)$ and needed management in 84 cases (52\%). Fetuses were stillborn in 44 cases $(27 \%)$.

Table 4: The sonographic features.

\begin{tabular}{|lcl|}
\hline \multicolumn{2}{|c|}{ No. of employees } & $\%$ \\
\hline \multicolumn{2}{|l|}{ Echographic diagnosis of age } & \\
\hline $1^{\text {st }}$ Trimester & 01 & 2.5 \\
\hline $2^{\text {nd }}$ Trimester & 09 & 22.5 \\
\hline $3^{\text {rd }}$ Trimestre & 30 & 75 \\
\hline Total & 40 & 100 \\
\hline Diagnostic error & & 86.7 \\
\hline $\begin{array}{l}\text { Defects not detected and } \\
\text { recovered at birth }\end{array}$ & 13 & 13.3 \\
\hline $\begin{array}{l}\text { Abnormalities detected } \\
\text { and not found at birth }\end{array}$ & 02 & 100 \\
\hline Total & 15 & \\
\hline
\end{tabular}

\section{DISCUSSION}

\section{Frequency}

The maternity of the CHU of Treichville is very frequented by the pregnant women; In fact, over the period of ten years that is spread out our study, we have recorded 30,698 births, with extremes of 180 to 3760 newborns per year. Congenital malformations were found in 161 babies, or $0.52 \%$ of births. This rate is similar to those of Coulibaly-Zerbo $\mathrm{F}$ and of LONGOMBE N. ${ }^{3,4}$ Who reported $0.41 \%$ at Cocody University Hospital (RCI) and $0.67 \%$ in Lubumbashi General Hospital (DRC), respectively. On the other hand, it is lower than those found by Goulet in Guadeloupe: $1.71 \%$ and De Vigan C. ${ }^{5,6}$ In Paris (France) with $3.2 \%$. We believe that this prevalence could be revised upwards if many files were not incomplete and autopsies were performed on newborn babies.

\section{Characteristics of patients}

The majority of our study participants were between 20 and 30 years old $(66 \%)$, were primiparous in $46.4 \%$ of the cases and $41.7 \%$ were homemakers. Regarding the age of the pregnant, our results agree with those of Amon-Tanoh-Dick F. ${ }^{7}$ At the CHU of Yopougon (RCI) and Coulibaly-Zerbo $\mathrm{F}$ but are different from those of Mayanda $\mathrm{H}$ in Congo Brazzaville where the pregnant women are more than 35 years old. ${ }^{7,8}$ Thus, although the risk of congenital malformations increases with maternal age, this fact was not observed during our study. Remember that high maternal age affects only the occurrence of chromosomal congenital malformations. Primitism predominated in our study as in Camara $\mathrm{M}$ at Yopougon University Hospital $(37.7 \%)$, contrary to the work of Amon-Tanoh-Dick F, Coulibaly-Zerbo $F$ and Mayanda $\mathrm{H}^{9}{ }^{9,7,3,8}$ Where the pregnant were pauciparous or multiparous in the direction of the literature that incriminates parity in the occurrence of malformations. The mothers of children with malformations were mainly housewives as in Coulibaly-Zerbo F. ${ }^{3}$ This epidemiological characteristic not studied in the other works does not allow us not to incriminate the profession as a factor in the occurrence of malformations.

\section{Abnormalities observed during the study}

In our study, there were more isolated malformations $(62.4 \%)$ than polymalformative syndromes. This is the same as Amon-Tanoh-Dick F, Mayanda $\mathrm{H}$ and Goulet with $66.29 \%, 76.9 \%$ and $75 \%$ of isolated malformations, respectively. ${ }^{7,8,5}$ The malformations observed during our study were dominated by those of the osteoarticular apparatus, followed by those of the central nervous system. These two groups of malformations have also been found in other research work. Thus Boussofara R. ${ }^{10}$ In Tunisia, the majority of the CNS malformations with $6.75 \%$ followed by those of the osteoarticular apparatus (4.23\%). Longombe $\mathrm{N}^{4}$ notes an increase in CNS malformations $(51.1 \%)$ and then osteoarticular apparatus with $13.1 \%$. Our results differ from those of AmonTanoh-Dick F, in whom digestive malformations predominate with $21.6 \%$, followed by those in the CNS $(21.5 \%) .^{7}$ Similarly, in Mayanda $\mathrm{H}$, the majority of gastrointestinal malformations $(24.3 \%)$ are followed by those of the CNS with $21.5 \% .^{8}$ Finally, Goulet in Guadeloupe has a predominance of CNS malformations $(3.8 \%)$ followed by those of the digestive tract $(2.45 \%) .^{5}$ These results are totally the opposite of those of De Vigan $\mathrm{C}$ in Paris which found mainly cardiac and chromosomal malformations, in neonates of mothers presenting factors of malformations (high maternal age and history of cardiac pathologies). ${ }^{6}$ The malformations of the osteoarticular and muscular system were dominated By club feet and omphalocele; As for those of 
the CNS, they were led by macrocephaly. Our results are consistent with those of Mayanda $\mathrm{H}$, concerning malformations of the osteoarticular system, but differ from those of the CNS, predominant by myelomeningoceles. ${ }^{8}$ Coulibaly-Zerbo $\mathrm{F}$ had a higher rate of polydactyly and microcephaly; While Chaaboun $\mathrm{H}$ in Tunisia found a majority of anencephaly. ${ }^{3,11}$ It finally emerges that fetal malformations differ according to the studies and the places but also of the technical platform for the antenal diagnosis.

\section{Characteristics of pregnancy, childbirth and condition of newborn antenatal diagnosis and mode of delivery}

55 out of 151 patients had an ultrasound before delivery. 40 of them had their diagnosis correctly laid, while the other 15 had a false diagnosis. However, this rate of $36.41 \%$ (55) of ultrasound performed during pregnancy is low and goes in the same direction as the study of Longombe $\mathrm{N}$ in Lubumbashi with $36 \%$ antenatal ultrasound compared with $84.9 \%$ in 2000 , antenatal ultrasound diagnosis in France according to the registers of INVS (National Institute of Health Watch). ${ }^{4,12}$ These figures show the effort to raise awareness of How with pregnant women in our developing countries for the proper follow-up of pregnancies. Similarly, 27.3\% of false diagnosis indicate the need for better training in prenatal diagnosis of imaging doctors.

Childbirth delivered a slight increase in childbirth with $53 \%$; This rate is superimposable to that of Camara $\mathrm{M}$ at the CHU de Yopougon, which counted $47.5 \%$ of cases. ${ }^{9}$ It is however below that of Mayanda $\mathrm{H}$ with $100 \%$ lowbirth delivery. ${ }^{8}$ This mode of delivery in our series can be explained by the discovery in the room of several malformations undiagnosed in antenatal (74\%), as well as the decision to privilege the low route in case of nonviability of the malformation detected in antenatal.

\section{State at birth}

The malformed newborns in our study were $75 \%$ eventually; There was a low male predominance $(55 \%)$ and the death rate was $27 \%$. In terms of gestational age, our results are in line with those of Amon-Tanoh-Dick F. (60\%), Coulibaly-Zerbo $\mathrm{F}(78 \%)$ and Longombe $\mathrm{N}$ $(64.9 \%))^{3,4,7}$ This high rate of newborn babies is linked to late ultrasound $(75 \%$ in the third trimester) and sometimes to parents' refusal to practice a GTI (religious reason or disbelief), preferring to arrive at the end of pregnancy. Male dominance is also found in almost all research. ${ }^{3,4,7}$

The rate of death on the other hand varies with an upward trend in our data; Amon-Tanoh-Dick F. has $48 \%$ of deaths, Boussofara R. $43 \%$ and Mandanda H. $76.6 \%$ of deaths. ${ }^{7,10,8}$ Only Goulet in Guadeloupe has a lower rate with $17 \% .^{5}$ This low death rate could be explained by the high technical plateau.

\section{Prognosis of malformations}

Of the malformations reported, $19 \%$ were poor prognosis (incompatible with life); This may explain the moderate death rate $(27 \%)$ found in the newborns of our study. However, some of the other malformations require care in the short or medium term so as not to increase the mortality rate in these children with malformations.

\section{CONCLUSION}

Congenital malformations are a reality at the maternity clinic at Treichville. Despite a prevalence of $0.59 \%$ of births, they should not be overlooked in the face of psychological trauma and prejudice. If antenatal diagnosis is virtually systematic in other areas, there is still a long way to go in developing countries to make the most effective antenatal diagnostic methods available to the population. While waiting for the ultrasound stays afundamental element for the congenital diagnosis of the moalformations, easily accessible to our regions. A good training of the doctors in prenatal diagnosis is also necessary to make of good diagnoses who will allow a better care of new-born.

Funding: No funding sources Conflict of interest: None declared Ethical approval: Not required

\section{REFERENCES}

1. OMS\Anomalies congénitales. Available form; www.who.int/mediacentre/factsheets/fs370/fr.

2. Benachi A, Parat S, Alvarez L. Prenatal diagnosis: From screening to fetal medicine National Committee of Childhood, Paris; 2011:27.

3. Coulibaly-Zerbo F, Amorissani-Folquet M, KacouKakou A. Epidemiological study of birth defects Black African Medicine. 1997;44(7):409-14.

4. Longombe N. Epidemiology of congenital malformations related to Lubumbashi (2004-2011). Great Lakes Medical Review. 2013;2(2):152-63.

5. Goulet $\mathrm{O}, \mathrm{Hochez} \mathrm{JC}$, Berchel. Incidence of congenital malformations at birth in a maternity Guadeloupe French Archives of Pediatrics. 1986;43(7):507-11.

6. DE Vigan C, Khoshnood B, A Lhomme Prevalence e prenatal diagnosis of defects in the Paris population: twenty years of monitoring by the register of congenital malformations of Paris J Obstetr Gynecol Reproduct Biol. 2005;34(1)8-16.

7. Amon-Tanoh-Dick F, Gouli JC, Ngouan- Domoua A, Aka J, Naponkini H. Epidemiology and become immediate malformations of the newborn, the CHU of Yopougon (Abidjan CI). Int Medic Sci. 2006;8(2):7-12.

8. Mayanda HF, Bobossi H, Malonga H. Congenital malformations observed in the neonatal unit of the hospital and university of Brazzaville Medicine of Black Africa. 1991;38:7. 
9. Camara M. Contribution to the analysis of the problems of diagnosis and management of fetal malformations in gynecology-obstétrique CHU Yopougon Brief in preparation for the CES of Gynecology -Obstétrique, ${ }^{\circ}$ 1044, Abidjan; 2003.

10. Boussofara R, Labbassi I, Bannour H. Incidence of major congenital malformations in the maternity Mahdia: About 79 cases. Maghreb J Pediatr. 2002;12:4:201-5.

11. Chaabouni H, Nemsia J, Riou S. Congenital malformations: a Tunisian maternity conducted the survey Maghreb Medical. 1986;129:49-54.
12. Institute of Health Watch. Available from; www.invs.sante.fr.

Cite this article as: Yao IN, Dia JL, Oyeladé MA, Bohoussou PK, N'guessan EK, Okon G et al.

Panorama of fetal malformations at the maternity of Treichville teaching hospital (Abidjan - Côte d'Ivoire). Int J Reprod Contracept Obstet Gynecol 2017;6:3230-4. 